\title{
Management and preservation techniques of non book materials in selected archival centres in Ernakulam district of Kerala
}

\author{
Manzoor Babu $\mathbf{V}^{1^{*}}$, Hasbi Alikunju ${ }^{2}$ \\ ${ }^{1}$ Librarian, ${ }^{2}$ Research Scholar, ${ }^{1}$ Farook College, Kozhikode, Kerala, ${ }^{2}$ Central University, Tamil Nadu, India
}

*Corresponding Author: Manzoor Babu. V

Email: manzoorbabu@farookcollege.ac.in

\begin{abstract}
In this article an attempt has been made by the investigators to study the preservation techniques employed by archival centres in management of archival documents in Ernakulam District. A combination of various methods Questionnaire, Interview and observation are employed for conducting the study. Selected archival centres are found practising various techniques for document management like classification, cataloguing, and automation etc. Most of the archival centres are following basic preservation techniques like lamination, acidification and fumigation etc. for preservation of documents.
\end{abstract}

Keywords: Libraries, Archives, Preservation, Non book materials, Archives management

\section{Introduction}

The word 'Archives' is defined in the 'oxford English dictionary' as 'A place in which public records or other historical documents are kept/ preserved or 'House of documents/ Records'. An Archive is a mine of information and a repository of records. The records kept in the archives reveal the past experience. Uses or value of archives can be classified into three categories. Historical value of archives is that Researcher of modern history can use it for their purpose of data collection of research. The archival documents are the treasures of all the facets of human life and also it portray the customs, conventions and usages of the people.. Various organization both public and private, need records for their day to day administration activities, so they maintain important records in archives and these records provide valuable information about previous governments and their administrative activities. It indicate the administration value of archives. By the intellectual value of archives, it helps to strengthen their democratic knowledge and form a public opinion by appreciating and criticizing Government policies and programmes.

Main functions of archives are collection of books, classification of records, preservation of records, supply of records for reference to government officers and researchers, publication of records, providing research hall facilities to researchers, provide library services, offering training programs and weeding up of records.

One of the primary functions of an archive is the preservation of records. It has two main aspects that, Preservation of records in good condition which are saved from future deterioration by proper housing, control of atmospheric conditions and precaution against insect attack and Rehabilitation of brittle, damaged or insect affected records.

\section{Principles of Preservation}

1. Careful handling of the objects which are in ruined condition.
2. To find out proper treatment for each type of deterioration.

3. Classify the objects on the basis of the degree of its deterioration.

4. For preservation only standardized material must be used.

5. All common products whose composition is unknown must not be used.

6. The preservatives are used only after testing.

7. A record of the nature of deterioration and the remedial measures taken should be maintained for future reference.

Environmental conditions such as heat, light, moisture, dust, insects, fungus, fire etc. cause deterioration of archival materials. The deterioration agents are broadly classified as biological (fungi, insects, rodents), physical (light, heat, humidity), chemical and atmospheric agents (temperature, wind).

There are various restoration techniques for preserving archival materials. This methods of conservation varies from material to material. Some of the methods are fumigation, pagination, bleaching method, re-sizing method, binding, tissue repair, chiffon repair, lamination, reprography, microphotography, wet method, leaf casting, ph testing, deacidification processes, encapsulation etc.

\section{Review of literature}

Adupa Sunil and K Praveen Kumar (2008) conducted a study on the topic "Preservation of library materials: Problems and Perspective". This paper gives an overviews of how to conserve library material. The keywords used are preservation, library materials and destructive agents. Questionnaire and interview are the tools used to gather the required data. The conclusion is that every professionals in libraries must draw the attention of the policy makes to the proper preservation techniques and their applications. For the purpose of further development of preservation of library materials, some steps to be taken into the consideration, that are 1) the latest preservation techniques have to be followed, 2) the library professionals must upgrade their technical 
expertise by taking orientation and training programmes on conservation of library materials. 3) Conservation techniques must find place in the curriculum of library sciences courses 4) good governance and best technical support for the strengthening of preservation of valuable books in libraries.

Alahakoon and Wimalaratne (2007) entitled "User attitude survey of usage, maintenance and preservation of major palm leaf manuscripts collections in Sri-Lanka" introduces the user attitudes related to the selected palm leaf collections in the country and the survey has conducted as a part of the main survey. The objective of the study was to identify the user attitudes regarding the usage, maintenance and preservation of palm leaves in 3 major collections in the country. Questionnaire method was method for data collection. Data analysis was done by using the analysis of Variance (ANOVA). The study finds that all the users have positive attitude of usage and maintenance. Based on the findings, there was no attitude difference between the repositories. The study give some suggestions to overcome the problems such as microfilming the collections, user awareness programs for usage, applying oil treatment, provide training for personal, restrict to use fragile copies and encourage using manuscripts for research.

Catherine Ogbodo (2010) conducted a study on the topic "Preservation of information sources in Polytechnic libraries in South East States of Nigeria". This study was aimed at examining the preservation of information sources in polytechnic libraries in South Eastern States of Nigeria. The entire population of 33 academic libraries was used for the study. A questionnaire was used to gather data and the results showed among others that were problems of preservation of information sources in polytechnic libraries in Nigeria. These polytechnic libraries use ineffective methods to combat the problems of preservation. It was recommended that adoption of digital technology in preservation among others could help these libraries preserve their materials effectively.

Harry Akussah (2005) conducted a study on "Preservation of public records in Ghana: the training, education and awareness factors". This study describes the institutional framework for records and archives management in Ghana and emphasizes the lack of awareness of document preservation issues among the staff of government registries, the national records centre and the national archives and among users of public records and archives. Outlines the facilities available for formal and informal staff training in preservation in Ghana and overseas and the need for awareness programmes for public servants and users of the national archives concludes that the lack of preservation training, education and awareness raising among both staff and users are key causes of document deterioration in Ghana and makes recommendations for remedial action by the authorities.
Jimmy Rakesh PR (2016) conducted a study "An analytical study on preservation and utilisation of manuscripts: with special reference to Calicut Regional Archives". The main objectives of the study were to assess the utilization of Calicut Regional Archives by the users and also to identify the existing methods of preservation and conservation of Calicut regional archives. Also to find out the problem faced by users while using Calicut regional archives. The main research tools used are literature survey, questionnaire and interview. The study finds that majority of users belongs to the Archives were research scholars and majority of the respondents spends more than three hours in the archives.

\section{Objectives of the study}

1. To determine the variety of non-book collections available in different archival centers in Ernakulam district.

2. Find out the techniques employed in the management and preservation activities by the archival centers with regards to non-book material.

3. Find out the problems and challenges of preservation of non-book materials in these archives.

4. Compare the preservation techniques employed by archival centers in Ernakulam district.

\section{Methodology}

There are different types of archives in our society, ie, they can be classified on the basis of the management under which they functioned. It may be government management, aided, unaided and co-operative management. The researcher selected four different archives in Ernakulam district Archdiocesan Archive, Ernakulam, Sree sankara Sanskrit university, kalady, Ernakulam, Regional archive, Ernakulam and St. Mary's cathedral basilica archive, Ernakulam. The techniques used for data collection are questionnaire, interview method and observation method. After collecting background information from selected archival centre, a survey was conducted using a questionnaire. A pre-structured questionnaire was prepared considering the objectives of the study and distributed it among the staffs of the selected archives. Interviews were conducted with the archivist and authorities of the selected archives. For additional information, observation method was adopted.

\section{Analysis and interpretation}

As already mentioned, researcher selected four archives based on different management. Two of them are government archives - Regional archive, Ernakulam and Sree sankara Sanskrit university, kalady, Ernakulam. Other two- St. Mary's cathedral basilica archive, Ernakulam and Archdiocesan Archive, Ernakulam, are unaided archives.

Table 1: 


\begin{tabular}{|c|c|c|c|c|}
\hline & $\begin{array}{c}\text { Regional } \\
\text { archive, EKM }\end{array}$ & $\begin{array}{c}\text { Sree sankara Sanskrit } \\
\text { university, kalady, } \\
\text { EKM }\end{array}$ & $\begin{array}{c}\text { Archdiocesan } \\
\text { Archive, EKM }\end{array}$ & $\begin{array}{c}\text { St. Mary's } \\
\text { cathedral basilica } \\
\text { archive, EKM }\end{array}$ \\
\hline $\begin{array}{l}\text { Use of classification schemes for the } \\
\text { arrangement of the materials in archives. }\end{array}$ & $\checkmark$ & $\checkmark$ & $\checkmark$ & $\mathrm{x}$ \\
\hline $\begin{array}{l}\text { Use of cataloguing rules for easy retrieval } \\
\text { of materials in Archives. }\end{array}$ & $\checkmark$ & $\checkmark$ & $\checkmark$ & $\mathrm{x}$ \\
\hline $\begin{array}{l}\text { Use of software packages for the proper } \\
\text { functioning of archives. }\end{array}$ & $\mathrm{x}$ & $\mathrm{x}$ & $\mathrm{x}$ & $\mathrm{x}$ \\
\hline $\begin{array}{l}\text { Clear policy for preservation and } \\
\text { management of non book materials. }\end{array}$ & $\checkmark$ & $\mathrm{x}$ & $\checkmark$ & $\checkmark$ \\
\hline Trained staff for managing the archives & $\checkmark$ & $\checkmark$ & $\checkmark$ & $\checkmark$ \\
\hline $\begin{array}{l}\text { Training workshops relating to the } \\
\text { preservation of archival materials }\end{array}$ & $\checkmark$ & $\checkmark$ & $\checkmark$ & $\checkmark$ \\
\hline $\begin{array}{l}\text { Annual funding sources for the } \\
\text { preservation procedures }\end{array}$ & $\checkmark$ & $\checkmark$ & $\mathrm{x}$ & $\checkmark$ \\
\hline
\end{tabular}

All the three archives except St. Mary's cathedral basilica archive, Ernakulam, Use classification schemes for the arrangement of the materials in archives. Sree Sankara Sanskrit University archive follows the classification scheme, New Catalogus Catalogorum s(NCC).

Alphabetical catalogue of all Sanskrit manuscript collections known at the time, present in a work titled, Catalogus Catalogorum. The Catalogus catalogorum contains a list of the various donations and their catalogues for a chronological survey. New Catalogus Catalogorum published by University of Madras total 42 volume has been published and some volume has been published with collaboration with NMM. The new Catalogus Catalogorum Project carried out in the department is nearing completion.

Regional Archive follows the Principle of provenance for the arrangement of archival materials. Provenance is a fundamental principle of archives, referring to the individual, family, or organization that created or received the items in a collection. The principle of provenance or the respect des fonds dictate that records of different origins (provenance) be kept separate to preserve their context. It states that " 1 . The process of organizing materials with respect to their provenance and original order, to protect their context and to achieve physical or intellectual control over the materials. 2. The organization and sequence of items within a collection".

Other two private archives, Archdiocesan Archive and St. Mary's cathedral basilica archive follow their own classification methods like chronology and alphabetical arrangement etc.

Three archives except Sree Sankara Sanskrit University have their own clear preservation policy. Preservation policy advocates that, appropriate scientific methods should be used for preservation of archival materials. Preservation techniques vary according to type of materials in archival collections. There cannot use same preservation procedures for each and every items. Also, preservation methods selected is based on the decision made by archivists.

All the four archives under study, has the trained staffs for managing and implementing the preservation techniques.
Sree sankara Sanskrit university archive, kalady, Ernakulam and St. Mary's cathedral basilica archive, Ernakulam have one trained staff each. Archdiocesan Archive, Ernakulam and Archdiocesan Archive, Ernakulam have 2 and 7 trained staffs respectively. The large number of staffs are engaged in Archdiocesan Archive it shows the affection made by the management towatds preservation of materials. Sree Sankara Sanskrit university archive is an emerging archive, in the present status there is a need of only one archivist.

Three archives have annual funding sources except Archdiocesan Archive, it is receiving fund as per requirement. Regional archive, Ernakulam receives funds from archaeological department of Kerala Government and Sree sankara Sanskrit university archive get grants from UGC or from other University sources. Archdiocesan Archive and St. Mary's cathedral basilica archive receive funds from their respective parent managements.

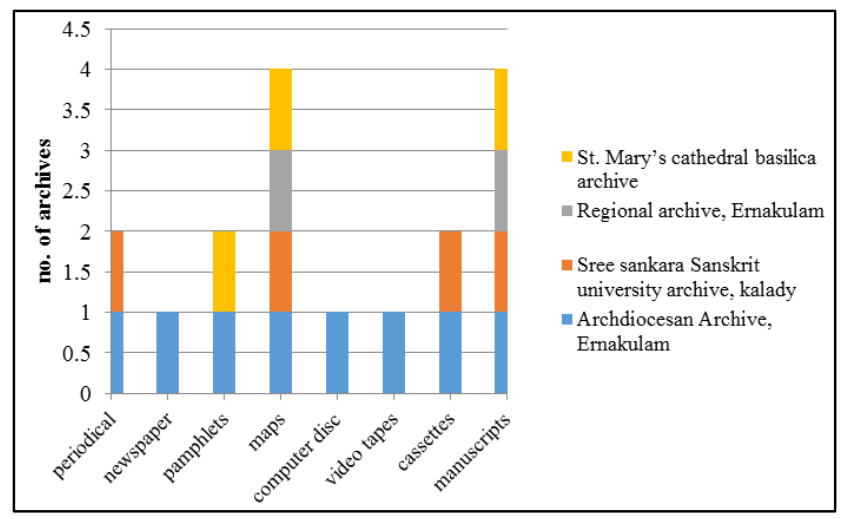

Fig. 1: Non book items available in Archives

From the graph, maps and manuscripts are preserved in the four archives. Newspaper, pamphlets, computer disc and cassettes are preserved only in Archdiocesan Archive, Ernakulam. And periodical and cassettes are properly conserved in both Archdiocesan Archive, Ernakulam and Sree Sankara Sanskrit University archive, kalady. 
Additionally, Regional archive have a very good collection of palm leaves, bamboo splint, copper plate, etc.

Archdiocesan Archive have more collection of archival materials, and it is functioning under a Christian church. They maintain the collection more systematically than 0ther archival centres. Regional archive also has a good collection various archival records and they are getting regular funding from the Government.

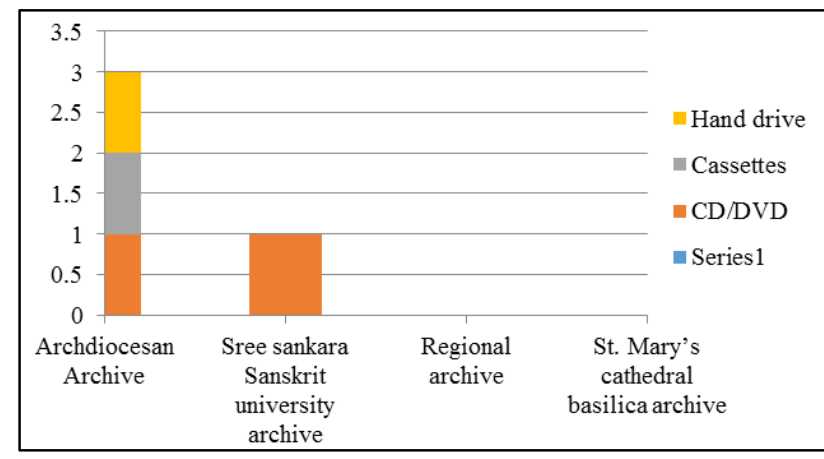

Fig. 2: Digital and electronic collections in archives.

From this, Archdiocesan Archive, Ernakulam and Sree Sankara Sanskrit University archive, are preserving digital and electronic items such as hard drive, cassettes and CD/DVD in their archives. Other two, Regional archive, Ernakulam and St. Mary's cathedral basilica archive are not managing any digital collections. Comparing to other archival centres, Archdiocesan Archive have the more collection of digital and electronic materials and they maintain the collection scientifically and systematically. In Regional archive and St. Mary's cathedral basilica, there is no any digital collection because may be lack of funds.

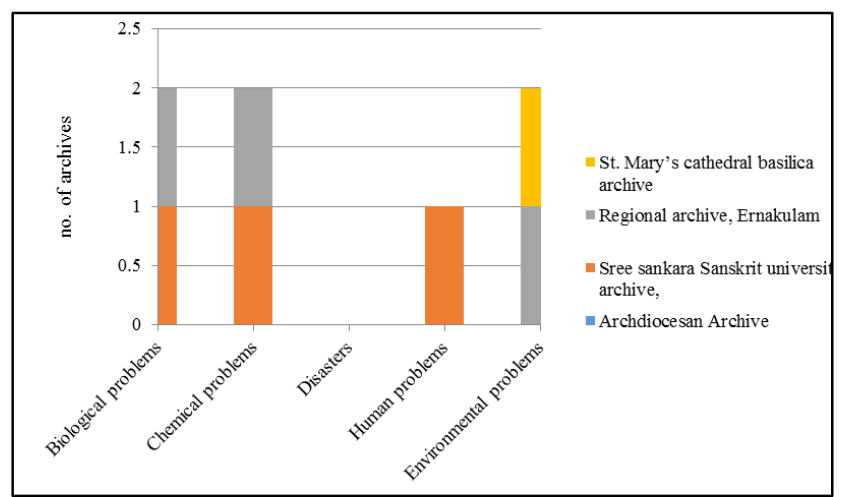

Fig. 3: Major areas of problems

From this figure, biological problems and chemical problems are main cause of deterioration of non book items in both Sree Sankara Sanskrit University archive and Regional archive, Ernakulam. Human problems are only affected in Sree sankara Sanskrit University archive. Environmental problems are affected in both Regional archive, Ernakulam and St. Mary's cathedral basilica archive. Disasters are does not marked as a cause of deterioration of non book materials in any of the selected archives.
Environmental problems, biological problems and chemical problems are the common problems suffered by most of the archives under study and this may be because of the improper construction of archival building and irregular caring of materials. Human problems are affected by only one archive that is due to lack of trained staff and increased usages by university students in that archive.

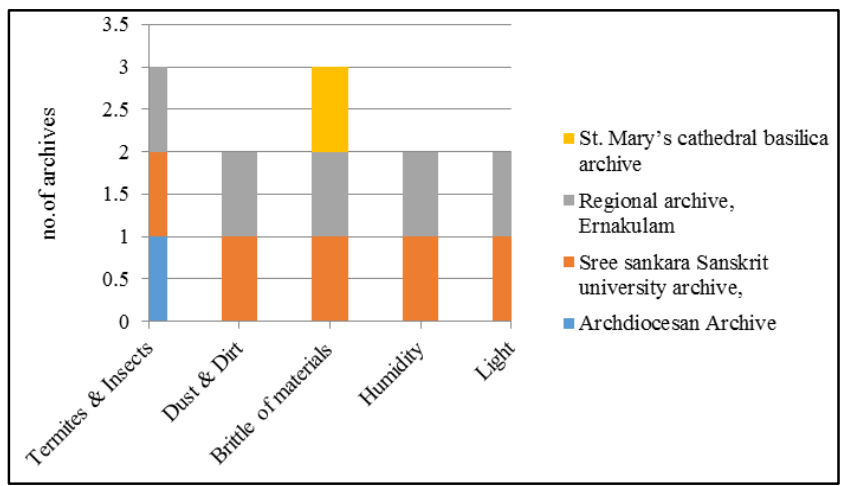

Fig. 4: Specific problems of deterioration in Archives

Sree sankara Sanskrit University archive and Regional archive, Ernakulam are mainly affected by dust \& dirt, humidity and light. Termites \& insects become a cause of deterioration in Archdiocesan Archive, Sree sankara Sanskrit University archive and Regional archive, Ernakulam. Also brittle of materials become a cause of deterioration in St. Mary's cathedral basilica archive, Sree sankara Sanskrit University archive and Regional archive, Ernakulam.

Most of the archives are suffered from the problems such as brittle of materials and Termites and insects. The only solution for that is proper dusting and cleaning regularly. Dust and dirt, humidity and light added with lack of care are main reasons behind the decay of archival centres. It can be solved by proper construction of building and regular dusting and cleaning.

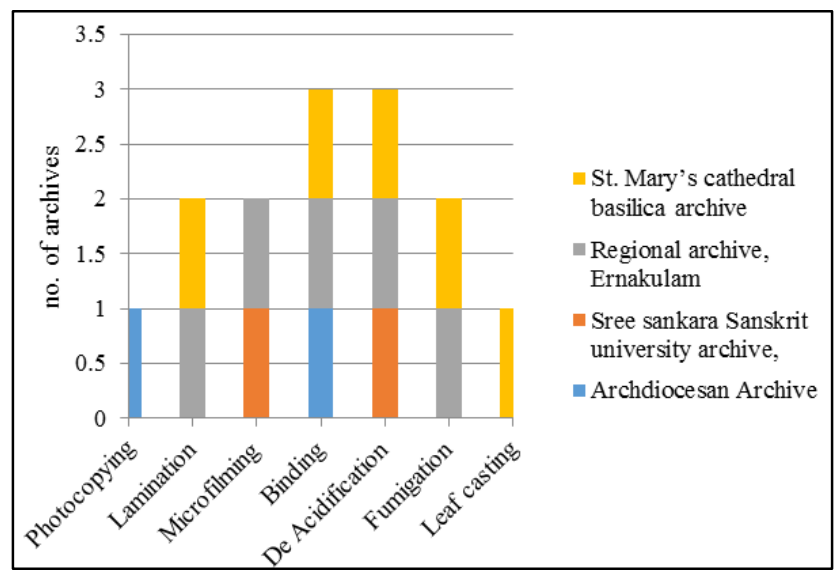

Fig. 5: Preservation techniques of Non-book items

From the figure, lamination and fumigation techniques are used in both St. Mary's cathedral basilica archive and Regional archive, Ernakulam. In Archdiocesan Archive, photocopying and binding are used as preservation 
techniques for non book items. In St. Mary's cathedral basilica archive, lamination, binding, de acidification fumigation and leaf casting techniques are used. Also de acidification techniques used in St. Mary's cathedral basilica archive, Regional archive, Ernakulam and Sree Sankara Sanskrit university archive.

In Sree Sankara Sanskrit university archive, they use grass oil for the preservation of manuscripts because it is the only suitable and natural chemical for the effective preservation of manuscripts.

Photocopying is only permitted in Archdiocesan Archive, but only for superior authority. In other three archives photocopying is not possible, but taking photographs are possible.

Binding and de acidification are the two effective methods for preservation, that's why they are the commonly used preservation methods. De acidification slows hydrolytic acidic degradation of paper. As of right now it will not make paper to regain its lost strength, but it will slow the degradation of paper that is strong but vulnerable to acid hydrolysis.

Fumigation, lamination and micro filming are the second most preferable techniques that widely used. Photocopying and leaf casting are very least used method for preservation in archives.

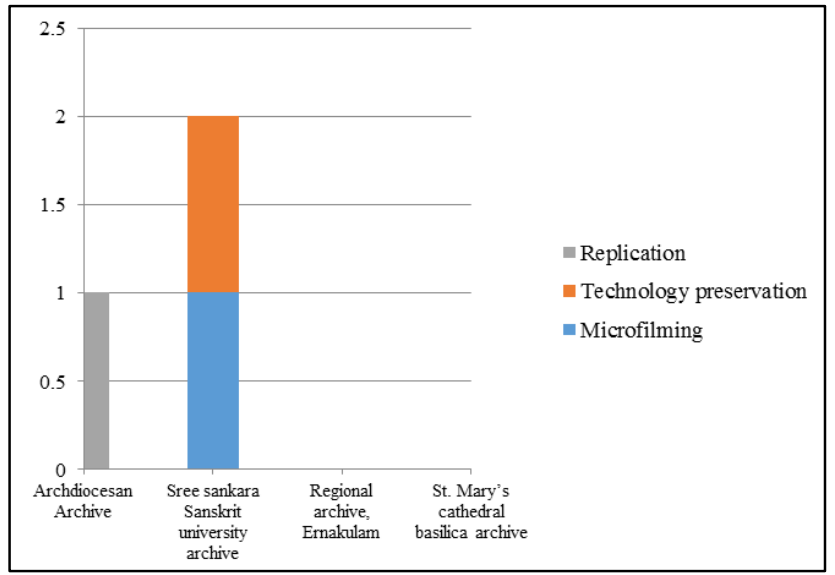

Fig. 6: Preservation techniques of Digital documents

St. Mary's cathedral basilica archive and Regional archive, Ernakulam does not preserve any digital collection and therefore they adopt no preservation techniques for digital collections. Archdiocesan Archive follows only replication technique for the preservation of digital collections. Technology preservation and microfilming procedures are used in Sree Sankara Sanskrit University archive.

Replication, Technology preservation and microfilming are the commonly used preservation techniques for digital documents and so they are the most effective method for it. Refreshing, migration, encapsulation etc are not used in any archives.

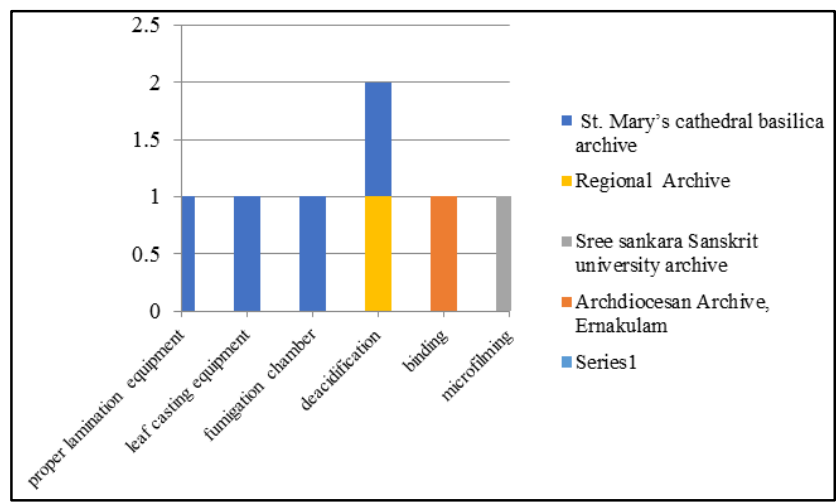

Fig. 7:

St. Mary's cathedral basilica archive has access to Proper lamination equipment, Leaf casting equipment, Fumigation chamber and Paper splitting equipment. Paper splitting and binding are also available in Archdiocesan Archive. Sree Sankara Sanskrit university archive has access to only microfilming facility. De-acidification facility is available in both St. Mary's cathedral basilica archive and Regional archive, Ernakulam.

Archdiocesan Archive is the archive having more facilities and big in size out of selected archives in Ernakulam district. Regional archive has very least facilities or equipment, this may be lack of adequate fund from Government.

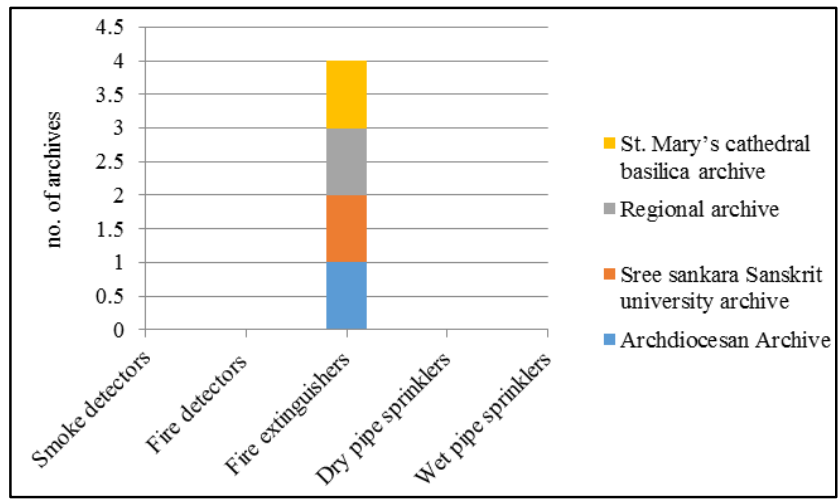

Fig. 8: Archive has fire detection/ suppression system

Only fire suppression system available in all the four archives is fire extinguisher because it is the most effective and scientific fire detection / suppression system. Fire detection/ suppression system such as Smoke detectors, Fire detectors, Dry pipe sprinklers and Wet pipe sprinklers are not much effective and therefore nobody uses these methods. 


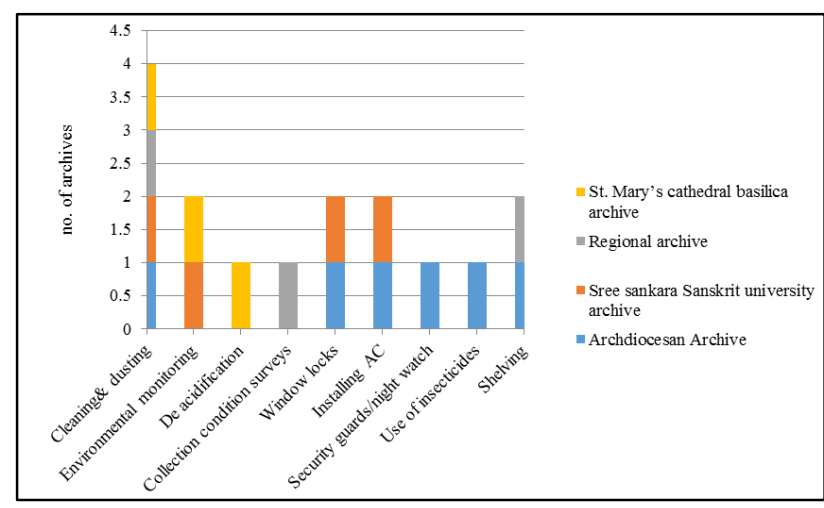

Fig. 9: Preventive preservation procedures in Archives

Security guards/night watch and Use of insecticides are used only by Archdiocesan Archive. Procedures such as window locks and AC installation are used by both Archdiocesan Archive and Sree sankara Sanskrit university archive. Cleaning and dusting is the common procedures, which is used by all the archives under study. De acidification is used only by St. Mary's cathedral basilica archive and collection condition survey is used only by Regional archive, Ernakulam. Archdiocesan Archive and Regional archive, Ernakulam are commonly using the shelving procedure. Sree sankara Sanskrit university archive and St. Mary's cathedral basilica archive commonly use the procedure environmental monitoring.

Archdiocesan Archive have followed a very good preventive preservation procedure because they have enough fund for maintaining their valuable and precious collection. Regional archive have poor preventive preservation procedure because of the lack of adequate fund from Government.

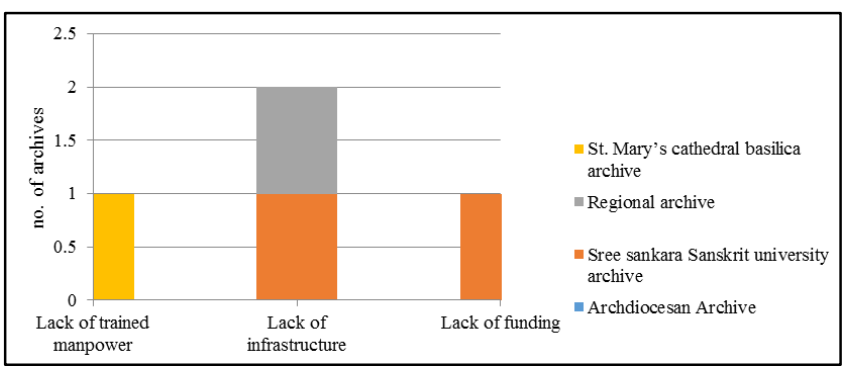

Fig. 10: Main hindrances to effective management and preservation practices

Lack of trained manpower is the main hindrances to the St. Mary's cathedral basilica archive and lack of adequate funding is the main hindrance to the Sree Sankara Sanskrit University. Regional archive, Ernakulam and Sree Sankara Sanskrit University are commonly affected harmfully by the lack of infrastructure.

Lack of trained manpower, lack of infrastructure and lack of adequate funding are the main hindrances affected by the selected archives in Ernakulam district. Administrative problems, harsh environmental conditions, outdated hardware \& software and lack written preservation policy are not marked as hindrances before the effective management and preservation in selected archives.

\section{Findings}

1. All the selected archives follow different types of classification schemes for the arrangement of the materials in archives.

2. Majority of the archives in Ernakulam District follow one or other cataloguing rules for the easy retrieval of the materials in archives.

3. Archives in Ernakulam does not use any software packages for the proper functioning of archives.

4. All the selected Archives have a good collection of nonbook items, manuscripts, maps, periodicals, etc.

5. Half of the selected archives have the collection of digital and electronic materials stored in Hard disks, CDs, cassettes etc. in their archives.

6. Majority of the selected archives have a clear preservation policy for management and preservation of non-book materials in archives.

7. Archives in Ernakulam District face the deterioration problems of non-book resources because of various reasons such as insects, Dust, Brittle of materials, Humidity, light etc.

8. All the selected archives in Ernakulam District employs various preservation techniques such as lamination, acidification, fumigation and leaf casting for preservation of non-book items in their archives.

9. Archives in Ernakulam District have good preservation techniques for digital collections in their archives.

10. Majority of the selected archives have trained staff for managing the archives.

11. All the selected archives have fire extinguisher system in their archives. No archive has facilities like smoke detector, fire detector, dry wipe sprinklers, and wet wipe sprinklers.

12. All the selected archives have preventive preservation procedures in their archives.

13. Archives generally suffer from the hindrances to effective management and preservation practices such as lack of trained manpower, lack of infrastructure and lack of funding.

14. All the selected archives facilitates to their staff to attend training workshops relating to the preservation of archival materials.

15. Majority of the selected archives have annual funding sources for the preservation procedures.

\section{Conclusion}

Archival collections generally experience from preserve and decay from aging. So there is a need for preservation and conservation of books, non-books and digital resources in archival centres. Preservation is the task of minimizing or reducing the physical and chemical deterioration of documents. In the selected archival centres in Ernakulam district, though they employ a variety of preservation techniques, it has not become in the international standard. 
Quick access to the materials also should be ensured by using appropriate management software.

\section{Source of Funding}

None.

\section{Conflict of Interest}

None.

\section{References}

1. Akande SO. "Knowledge, perception and Attitudes of library personnel towards preservation of Information Resources in Nigerian Federal University Libraries". Library philosophy and Practice.(2009) Retrieved from http://www.vidaho.edu/mbolin.htm.on 21st January, 2011 (pdf.)

2. Akussah H. "The Preservation of Traditional Library and Archival Materials in the Harsh Ghanaian Environment". Afr J Libr, Arch Inf Sci 1991;1(1):19-28.

3. Arizona. "Preservation Arizona State Library, Archives and Public Record, A division of Secretary of State". (2010)

4. Baker N. "Conservation and Preservation: A Problem of Library Management: A British view”. Libri 1981;31(3):197.

5. Bakhshi, Samar I. "Digitization and Digital Preservation of Cultural Heritage in India with Special Reference to IGNCA, New Delhi”. Asian Jf Inf Sci Technol 2016;6(2):1-7.The Research Publication. Web. 13 January 2018.

6. Danladi, D and Haruna, I. "Preservation Conservation and Restoration of Information Resource in selected Federal Polytechnic libraries in North East Zone of Nigeria". Afr J Educ Inf Manag 2009;10(1):24-31.

7. Edhebe C. "The Preservation and Conservation of Materials in the college of Education Library, Warri. Abraha: Delta State University". (2004).
8. Fadeham, O. "Preservation and conservation of newspapers in Nigerian University Libraries". Paper presented at the workshop on National Policy on Preservation of National Documentary Heritage. Abuja. 2009:24-7.

9. Jantz, R. and Gialio, M. J "Digital preservation. Architecture and Technology for trusted digital repository". D-Lib Magazine 2005;11(6).Web. May 15, 2009

10. Kemoni HN. "Preservation and Conservation of Archive Materials: The case of Kenya". Afr J Libr, Arch Inf Sci 1996;6(1):46-51. Web. 14 February 2018.

11. Olatokun W. M. "Survey of preservation and conservation practices and techniques in Nigeria University Libraries". Libr Inf Sci Res (UBRE). 2008;18(2). Web. 19 February 2018.

12. Joseph OP, Mnjama N. "Archival Preservation practices at the records and archives management department in Tanzania". Open J Sys 2014;32(3):136-65. EBSCO. Web. 16 January 2018.

13. Savant S. "A Study in Preservation and Conservation Practices in Academic Libraries in Mumbai". Annals of Library and Information Studies.61 (2014):153-159. Web. 12 January 2018.

14. Benegal VJ. "Archiving \& preservation of Information Initiatives at Raman Research Institute (RRI)". SRELS Journal of Information Management. 51.3(2014). Inf J 12 January 2018.

15. Mahmood Z. "Conservation and preservation of manuscripts in Rampur Raza Library, Uttar Pradesh: An overview ". Libr Herald. 2016;54(3). Research Gate. Web. 16 January 2018.

How to cite: Babu MV, Alikunju H. Management and preservation techniques of non book materials in selected archival centres in Ernakulam district of Kerala. IP Indian J Libr Sci Inf Techno 2020;5(1):1-7. 